\title{
Effect of bacterial lipopolysaccharide on gastric emptying of liquids in rats
}

E.F. Collares

\author{
Correspondence \\ E.F. Collares \\ Departamento de Pediatria \\ Faculdade de Ciências Médicas \\ Universidade Estadual de Campinas \\ 13081-970 Campinas, SP \\ Brasil
}

Publication supported by FAPESP

Received March 12, 1996

Accepted December 5, 1996

\author{
Departamento de Pediatria and Núcleo de Medicina e Cirurgia Experimental, \\ Faculdade de Ciências Médicas, Universidade Estadual de Campinas, \\ 13081-970 Campinas, SP, Brasil
}

\begin{abstract}
The objectives of the present investigation were 1) to study the effect of bacterial lipopolysaccharide (LPS) on rat gastric emptying (GE) and 2) to investigate a possible involvement of the vagus nerve in the gastric action of LPS. Endotoxin from E. coli (strain 055:B5) was administered $s c$, ip or $i v$ to male Wistar rats (220-280 g body weight) at a maximum dose of $50 \mu \mathrm{g} / \mathrm{kg}$ animal weight. Control animals received an equivalent volume of sterile saline solution. At a given time period after LPS administration, GE was evaluated by measuring gastric retention $10 \mathrm{~min}$ after the orogastric infusion of a test meal (2 $\mathrm{ml} / 100 \mathrm{~g}$ animal weight), which consisted of $0.9 \% \mathrm{NaCl}$ plus the marker phenol red $(6 \mathrm{mg} / \mathrm{dl})$. One group of animals was subjected to bilateral subdiaphragmatic vagotomy or sham operation 15 days before the test. A significant delay in GE of the test meal was observed $5 \mathrm{~h}$ after $i v$ administration of the endotoxin at the dose of $50 \mu \mathrm{g} / \mathrm{kg}$ animal weight. The LPS-induced delay of GE was detected as early as $30 \mathrm{~min}$ and up to $8 \mathrm{~h}$ after endotoxin administration. The use of different doses of LPS ranging from 5 to $50 \mu \mathrm{g} / \mathrm{kg}$ animal weight showed that the alteration of GE was dose dependent. In addition, vagotomized animals receiving LPS displayed a GE that was not significantly different from that of the sham control group. However, a participation of the vagus nerve in LPS-induced delay in GE could not be clearly demonstrated by these experiments since vagotomy itself induced changes in this gastric parameter. The present study provides a suitable model for identifying the mechanisms underlying the effects of LPS on gastric emptying.
\end{abstract}

Key words - Gastric emptying - Lipopolysaccharide - Vagus nerve

Natural infection or parenterally administered lipopolysaccharide (LPS) of bacterial origin can result in various clinical manifestations in several animal species (1-3). In the gastrointestinal tract, bacterial endotoxins induce severe intestinal mucosal injury frequently accompanied by diarrhea and enteric bacterial translocation (4-6). It has been suggested that vascular damage may play a role in the pathogenesis of LPS-induced acute diarrhea (4). In addition, LPS at sublethal doses suppresses gastric motility as suggested by the LPS-induced inhibition of gastric emptying of liquids and solids observed in mice and rats $(7,8)$. The mechanisms underlying the toxic actions of endotoxins on gastric emptying remain unexplored.

The aim of the present study was to examine the effect of LPS from $E$. coli on gastric emptying of a saline solution in rats 
evaluating the optimum route of administration, dosage and time following administration of the endotoxin. After this preliminary phase of the study, the second part was set up to determine vagal involvement in the LPS-induced alteration of gastric emptying.

Male Wistar rats (SPF, Biotério Central, Universidade Estadual de Campinas, Brazil) aged 8-10 weeks and weighing 220-280 g were employed. The rats were allowed to habituate to the laboratory environment for at least 15 days before any experimental manipulation. The animals were collectively housed and kept under conditions of controlled temperature $\left(22-26^{\circ} \mathrm{C}\right)$ and artificial dark-light cycle of $12 \mathrm{~h}$. They were fed on a standard rat chow (Labina, Purina) and received water ad libitum.

Before the test day, the rats were transferred to individual cages and subjected to a 20-h fasting period during which only water was available. LPS from $E$. coli (strain 055:B5, Sigma) was dissolved in $0.9 \%$ nonpyrogenic sterile $\mathrm{NaCl}$ and administered at a maximum dose of $50 \mu \mathrm{g} / \mathrm{kg}$ animal weight. Three different administration routes were employed for LPS injection: intravenous (iv) using the tail vein, subcutaneous $(s c)$ at the external region of the posterior limbs and intraperitoneal (ip). Control injections consisted of an equivalent volume of the appropriate vehicle $(1 \mathrm{ml} / \mathrm{kg}$ animal weight).

Gastric emptying was evaluated $5 \mathrm{~h}$ after parenteral administration of the endotoxin, except in the experiment testing the time dependence of the gastric response to LPS when the measurement of gastric emptying was performed at different times (up to $24 \mathrm{~h}$ ) after $i v$ injection of endotoxin. Gastric emptying was indirectly evaluated by determining the percentage of gastric retention (\%GR) of a phenol red-containing test meal recovered within the gastric content as compared to that orally administered $(9,10)$. Gastric retention was measured $10 \mathrm{~min}$ after orogastric infusion of the test meal in a vol- ume of $2 \mathrm{ml} / 100 \mathrm{~g}$ animal weight. The test meal consisted of an aqueous solution of $0.9 \% \mathrm{NaCl}$ containing $6 \mathrm{mg} / \mathrm{dl}$ phenol red as a marker. Saline solution has been considered a suitable test meal to evaluate gastric emptying without intestinal interference since there is no activation of intestinal receptors in contrast to that obtained with nutritive test meals (11).

In addition, a group of animals were subjected to bilateral subdiaphragmatic vagotomy 15 days before the test day (12). Sham surgery was also perfomed in some animals by executing laparotomy without the section of the vagus (12). Data for animals displaying severe gastric stasis after vagotomy were excluded from data analysis.

Data are reported as means \pm SEM (number of animals). The Student $t$-test $(\mathrm{k}=2)$ or analysis of variance $(\mathrm{k} \geq 3)$ followed by the Tukey test were used for statistical analysis of the data, with the level of significance set at $\mathrm{P}<0.05$. Correlation coefficients were calculated for the dose-response data.

The results of the present study showed that $5 \mathrm{~h}$ after $i v$ administration of LPS $(50 \mu \mathrm{g} /$ $\mathrm{kg}$ animal weight), the treated animals presented a significantly higher percentage of GR of the test meal than the control group (\%GR after $10 \mathrm{~min}$, control $=34.8 \pm 3.2 \%(\mathrm{~N}$ $=8)$, treated $=63.6 \pm 2.3 \%(\mathrm{~N}=8) ; \mathrm{P}<0.05$, $t$-test). In contrast, when the endotoxin was administered $s c$ or $i p$ using the same experimental protocol as employed above, no statistical difference in GR was observed between the control and treated groups (\%GR after 10 min, control $s c=33.2 \pm 2.1 \%(\mathrm{~N}=$ 8) $v s$ treated $s c=33.7 \pm 2.2 \%(\mathrm{~N}=8)$; control ip $=33.7 \pm 2.2 \%(\mathrm{~N}=8) v s$ treated ip $=41.1 \pm 2.2 \%(\mathrm{~N}=8))$.

To determine the dose dependence of this LPS-induced alteration of gastric emptying, different doses of LPS (ranging from 5 to $50 \mu \mathrm{g} / \mathrm{kg}$ animal weight) injected only $i v$ were tested. As shown in Figure 1A, there was a close correlation between increasing doses of LPS and the intensity of the in- 
crease of gastric retention induced by the endotoxin (correlation coefficient, $r=0.97$ ). Among the doses tested, 25 and $50 \mu \mathrm{g} / \mathrm{kg}$ of LPS were effective in significantly increasing GR of a saline solution in rats $(\mathrm{P}<0.05$ compared to the control group, Tukey test).

Figure 1B shows the time-response effect of the endotoxin. For this set of experiments, GR was determined $0.5,2,5,8$ and 24 $\mathrm{h}$ after $i v$ administration of $50 \mu \mathrm{g} / \mathrm{kg}$ LPS. The endotoxin induced a rapid and sustained increase in GR of the saline solution since significant differences between the treated group and its respective controls $(\mathrm{P}<0.05$, Tukey test) were observed as early as $30 \mathrm{~min}$ and up to $8 \mathrm{~h}$ after endotoxin administration. However, LPS was not effective in inducing this gastric effect $24 \mathrm{~h}$ after its administration (Figure 1B).

In the last part of the present study, we determined whether vagal innervation of the stomach was involved in the LPS-induced delay of gastric emptying. Figure 2 shows the results obtained. When the two subgroups treated with the endotoxin for $5 \mathrm{~h}$ were compared, the vagotomized animals showed significantly lower \%GR values than the sham-operated animals $(\mathrm{P}<0.05$, Tukey test $)$. These data suggest that the vagus might mediate, at least partially, the action of LPS upon gastric emptying. However, vagotomy itself had an effect on GR as indicated by the fact that vagotomized control animals displayed significantly lower \%GR values than the sham control group $(\mathrm{P}<0.05$, Tukey test $)$.

In conclusion, the present data clearly demonstrate that LPS from $E$. coli induces a significant delay of gastric emptying of an aqueous solution in rats. This alteration of gastric function was closely dependent on the administration route, dosage and time after administration of the endotoxin. This gastric disturbance was observed with considerably lower doses of LPS as compared to those employed in previous studies $(7,8)$. Concerning the vagal involvement in the phenomenon, bilateral vagotomy seems to
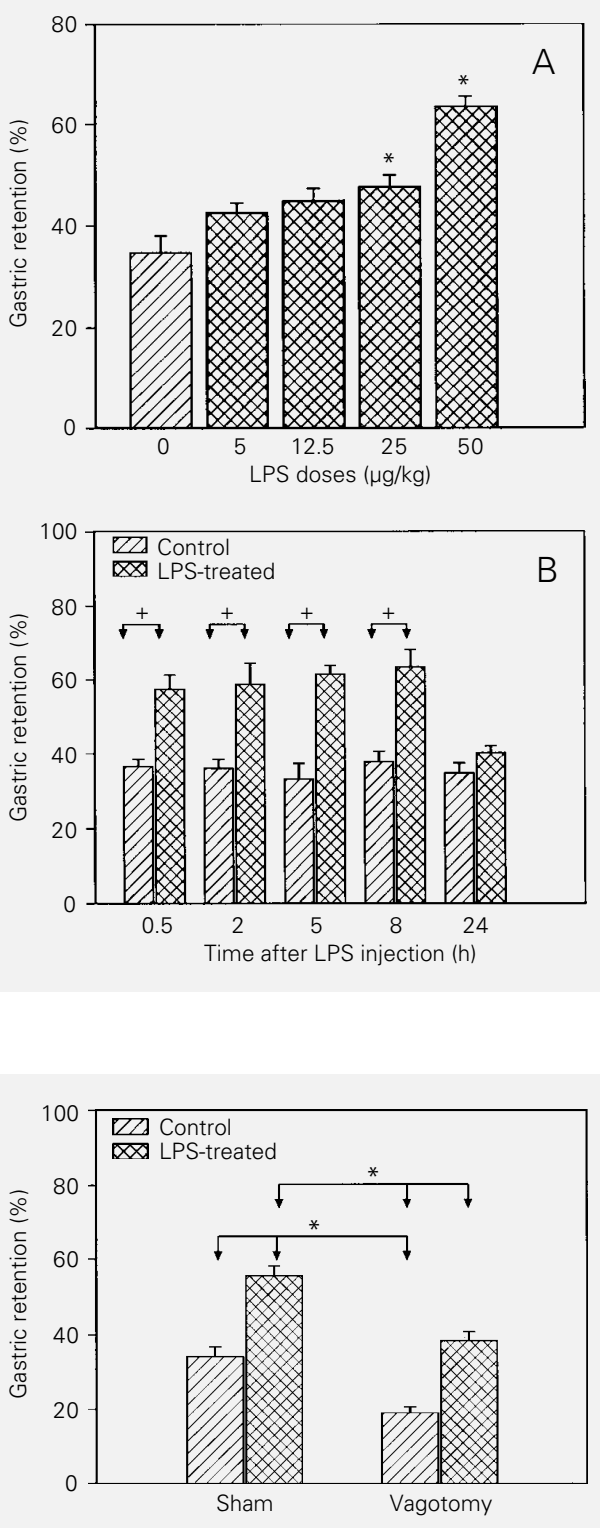

"normalize" the gastric emptying process in rats treated with LPS since their \% GR values were partially restored to control values (Figure 2 compares sham controlvs sham-treated and sham control $v s$ vagotomized-treated groups). These data suggest that the vagus nerve may play a role in the endotoxin-induced change in gastric emptying. It is well established that afferent and efferent vagal innervation of the stomach modulates the gastric motility and function via vagal cholinergic excitatory fibers and non-adrenergic
Figure 1 - Effect of E. coli lipopolysaccharide on gastric retention of $0.9 \% \mathrm{NaCl}$ by rats. $A$, Gastric retention was evaluated $5 \mathrm{~h}$ after the iv administration of different LPS doses. B, Gastric retention was determined 0.5 , $2,5,8$ and $24 \mathrm{~h}$ after iv administration of $50 \mu \mathrm{g} / \mathrm{kg}$ LPS. Control groups received vehicle instead of endotoxin. Data are reported as means \pm SEM for 8 animals (panel A) or 6 animals (panel B) in each subgroup. ${ }^{*} \mathrm{P}<0.05 \mathrm{com}$ pared to control group (Tukey test). $r=0.97$ for dose-response correlation. ${ }^{+} \mathrm{P}<0.05$ compared to control group (Tukey test).

Figure 2 - Effect of vagotomy on the E. coli lipopolysaccharide (LPS)-induced increase in gastric retention of $0.9 \% \mathrm{NaCl}$ solution by rats. The animals were subjected to bilateral subdiaphragmatic vagotomy 15 days before the test. Gastric retention was evaluated $5 \mathrm{~h}$ after the $i v$ administration of LPS $(50 \mu \mathrm{g} / \mathrm{kg}$ animal weight). The control subgroups received vehicle instead of endotoxin. Data are reported as means \pm SEM for 8 animals in each subgroup. The \%GR values between control and treated groups were significantly different. ${ }^{*} \mathrm{P}<0.05$ compared to the indicated experimental group (Tukey test). 
and non-cholinergic inhibitory fibers (13). The faster gastric emptying of liquids observed in the present study after sectioning of the vagus trunk has also been described by others (13). However, the above conclusion drawn from the present data seems not to be straightforward since vagotomy itself had an effect on gastric emptying. In this respect, one may suggest that the sectioning of the vagus nerve does not block the effect of endotoxin on gastric emptying since the injection of LPS induced a two-fold increase in \%GR in the vagotomized group (vagotomized control $\% \mathrm{GR}=19.1 \%$, vagotomized LPS $=38.4 \%$ ), similar to the values observed in the sham group (sham control $\% \mathrm{GR}=34.2 \%$, sham LPS $=55.6 \%$ ).

Further work is needed to identify the exact mechanisms by which the E. coli endotoxin affects gastric motility. An attractive possibility is that LPS induces alterations in the paracrine control of gastric emptying via locally released cytokines. For instance, endotoxin-induced intestinal vascular damage is known to be mediated by cytokines such as nitric oxide, platelet-activating factor and thromboxane A2 (14). Alternatively, the LPS-induced gastric disturbance may be the result of an action of this bacterial endotoxin on specific areas of the CNS which control some of the gastric functions via the vagus nerve. Several studies have demonstrated that certain hypothalamic nuclei, e.g., the paraventricular (12) and dorsomedial nuclei (15), can modulate the motor activity of the gastrointestinal tract. In addition, several reports have provided evidence for a vagal and central action of LPS. For instance, endotoxin from $E$. coli can induce 1) a fever response in rabbits when administered intracerebroventricularly (16), and 2) activation of hypothalamic histaminergic neurons in rats leading to ACTH release (17). In addition, a recent study has demonstrated that subdiaphragmatic vagotomy can suppress the endotoxin-induced activation of hypothalamic corticotropin-releasing hormone and ACTH secretion (18).

\section{Acknowledgments}

The author would like to thank Dr. Carla B. Collares-Buzato (Departamento de Fisiologia e Biofísica, UNICAMP, Brazil) for critically reviewing the English text, Ms. Maria Cristina Fernandes Alvin for technical support and Ms. Irani Ribeiro for typing the manuscript. 


\section{References}

1. Stetson Jr CA (1961). Symposium on bacterial endotoxins. IV. Immunological aspects of the host reaction to endotoxins. Bacteriological Reviews, 25: 457-458.

2. Zweifach BW \& Janoff A (1965). Bacterial endotoxemia. Annual Review of Medicine, 16: 201-220.

3. Kluger MJ (1991). Fever: Role of pyrogens and cryogens. Physiological Reviews, 71: 93-127.

4. Mathan VI, Penny GR, Mathan MM \& Rowlewy D (1988). Bacterial lipopolysaccharide-induced intestinal microvascular lesions leading to acute diarrhea. Journal of Clinical Investigation, 82: 1714-1721.

5. Fink MP (1991). Gastrointestinal mucosal injury in experimental models of shock, trauma, and sepsis. Critical Care Medicine, 19: 627-641.

6. Wells CL, Barton RG, Wavatne CS, Dunn DL \& Cerra FB (1992). Intestinal bacterial flora, intestinal pathology, and lipopolysaccharide-induced translocation of intestinal bacteria. Circulatory Shock, 37: 117123.

7. Turner MM \& Berry LJ (1963). Inhibition of gastric emptying in mice by bacterial endotoxins. American Journal of Physiology, 205: 1113-1116.

8. Langhans W, Harlacher R, Balkowski G \& Scharrer E (1990). Comparison of the effects of bacterial lipopolysaccharide and muramyl dipeptide on food intake. Physiology and Behavior, 47: 805-813.
9. Belangero VMS \& Collares EF (1991). Esvaziamento gástrico e acidose metabólica. I. Estudo de um modelo experimental em ratos, empregando uma solução de cloreto de amônio por via orogástrica. Arquivos de Gastroenterologia, 28: 145150.

10. Bucaretchi F \& Collares EF (1996). Effect of Phoneutria nigriventer spider venom on gastric emptying in rats. Brazilian Journal of Medical and Biological Research, 29: $205-211$.

11. Hunt JN (1983). Mechanisms and disorders of gastric emptying. Annual Reviews of Medicine, 31: 219-229.

12. Collares-Buzato CB, Collares EF \& Fernandes GA (1993). Effect of paraventricular nucleus lesion and cold restraint stress on gastric emptying of a liquid meal in rats. Brazilian Journal of Medical and Biological Research, 26: 1009-1014.

13. Kelly KA (1984). Effect of gastric surgery on gastric motility and emptying. In: Akkermans LMA, Johnson AG \& Read NW (Editors), Gastric and Gastroduodenal Motility. Praeger Publishers, New York.

14. Stark ME \& Szurszewshi JH (1992). Role of nitric oxide in gastrointestinal and hepatic function and disease. Gastroenterology, 103: 1928-1949.
15. Greenwood B \& DiMicco JA (1995). Activation of the hypothalamic dorsomedial nucleus stimulates intestinal motility in rats. American Journal of Physiology, 268 (Gastrointestinal and Liver Physiology, 31): G514-G521.

16. Macari M, Pela IR, Silva CAA \& Viana RS (1990). Fever response induced by intravenous and intracerebroventricular injection of pyrogen in thyroidectomised and protein-calorie malnourished rabbits. Pflügers Archiv: European Journal of Physiology, 15: 440-443.

17. Knigge $U$, Kjaer A, Jorgensen $H$, Garbarg M, Ross C, Rouleau A \& Warberg J (1994). Role of hypothalamic histaminergic neurons in mediation of ACTH and beta-endorphin responses to LPS endotoxin in vivo. Neuroendocrinology, 60: 243-251.

18. Gaykema RPA, Dijkstra I \& Tilders FJH (1995). Subdiaphragmatic vagotomy suppresses endotoxin-induced activation of hypothalamic corticotropin-releasing hormone neurons and ACTH secretion. Endocrinology, 136: 4717-4720. 